\title{
The Intergenerational Consequences of Climate Change on Later Life Mortality: Evidence from Individual-Level U.S. Death Records
}

\author{
Nathan Seltzer \\ University of California, Berkeley \\ nseltzer@berkeley.edu
}

Draft: 4/28/2021

\begin{abstract}
Global climate change can impact populations rapidly through the increased occurrence of natural disasters and climate extremes, but also through long-term, gradual changes that alter environmental conditions and impair biological processes. Here, I investigate whether ambient temperatures in utero and during the early years of life are associated with reductions in life expectancy. I combine monthly, statelevel climatological data from the National Oceanic and Atmospheric Administration with highresolution, individual-level mortality data from the CenSoc Project, which consists of cleaned and harmonized Social Security Administration death records from 1988-2005. Results indicate that exposure to higher ambient temperatures during gestation and the first four years of life are associated with increased mortality risk in later life for white men from low socioeconomic status backgrounds, but not other groups. It is likely that the effect of climate variability on later life mortality for non-white men is overshadowed by structural systems of racism that impact health stratification. Overall, the results emphasize how climate change has already begun to imprint itself onto demographic processes.
\end{abstract}

\section{BACKGROUND}

In recent years, demographers and other social scientists have investigated the potential implications of climate change on population processes, including mortality, fertility, and migration (Deschênes \& Greenstone, 2011; Hauer et al., 2019; Zanobetti \& O'Neill, 2018). Shifts in global climate since the start of the $20^{\text {th }}$ century have resulted in an estimated global temperature increase of 1.6 degrees Fahrenheit, and forecasts for this century suggest a 2.5 to 10 degrees Fahrenheit increase by 2100 (IPCC 2018). Global climate change can impact populations rapidly through the increased occurrence of natural disasters and climate extremes (Kanner et al., 2020; Luber \& McGeehin, 2008; McMichael et al., 2006; Seltzer \& Nobles, 2017), but also through long-term, gradual changes that alter environmental conditions and subsequently impair biological processes (Catalano et al., 2008; Curtis \& Schneider, 2011; Molina \& Saldarriaga, 2016).

In particular, prior work has sought to identify how changes in ambient temperature are associated with health and mortality (Basu \& Samet, 2002). In the short-term, higher ambient temperatures are associated with immediate increases in mortality for populations (Medina-Ramon et al., 2006), although the strength of this relationship has declined over the $20^{\text {th }}$ century in the U.S. as electricity and air conditioning became more widespread (Barreca et al., 2016). Prior findings have also documented how ambient temperatures in utero and during the early developmental period of life are associated with increased risk of stillbirths, decreased birth weight, and shorter aggregate lifespan for birth cohorts (Catalano et al., 2008; Catalano et al., 2011; Chen et al., 2020; Strand et al., 2011). Research examining adjacent, nondemographic outcomes of ambient temperature during gestation and early life have similarly found laterlife associations in the domains of education, employment, and earnings (Barron et al., 2018; Isen et al., 
2017). Yet, less is known about the longer-run consequences of increased ambient temperatures on later life mortality risk.

This study examines how ambient temperature during gestation and during the early developmental years of life are associated with later life mortality, beginning at age 65 and extending to 100 (median age of study sample at death, 79 years old for women and 75 years old for men). To conduct this analysis, I use data from the CenSoc Project (Goldstein et al. 2020), a cleaned and harmonized data source of Social Security Administration death records from 1988-2005, in conjunction with historical climatological records aligned with the month and year of birth of decedents. The results demonstrate gender-specific patterns of mortality that align with previous literature on ambient temperature in utero and cohort lifespan (Catalano et al., 2008), but provide new insight into the scope conditions under which social conditions dampen the detection of the effects of ambient temperature on later life mortality. The results presented here contribute to theoretical debates concerning climate change and mortality, as well as the developmental origins of health literature (Bateson \& Gluckman, 2012; Montez \& Hayward, 2011).

\section{DATA and METHODS}

I investigated the relationship between pre-natal/early-life ambient temperature on later life mortality by combining monthly, state-level climatological data from the National Oceanic and Atmospheric Administration (NOAA) with high-resolution, individual-level mortality data from the CenSoc Project at the University of California, Berkeley (Goldstein et al. 2020). Using data on decedents birth year, birth month, and birth state, I aligned measures of ambient temperature with the pre- and post-natal periods of life that were specific to each decedent.

\section{Ambient Temperature}

I accessed monthly, state-level weather data that spans the years 1895-1940 from NOAA's Climate Divisional Database (nCLIMDIV). This high detail dataset is constructed from a combination of historical weather station data and computational interpolation approaches. The data used include information on the average monthly temperature and the average maximum temperature (both in degrees Fahrenheit).

\section{Mortality Data}

I obtained individual-level mortality records from the Berkeley Unified Numident Mortality Database (BUNMD), a cleaned and harmonized dataset of Social Security application records publicly released by the National Archives and Records Administration (NARA). This micro-level dataset includes records on over 49 million decedents who passed away between 1971-2007. To leverage data that had the highest coverage of deaths, I focused my analysis on a subset of decedents who died between 1988-2005 and who were age 65 or older at the time of death. This resulted in a sample size of $\mathrm{N}=9,369,092$ for women and $\mathrm{N}=8,501,919$ for men.

Figure 1 presents a histogram that shows the distribution of age at death, the dependent measure, for the analytic sample, separately for women and men.

\section{Methodology}

Using data from the nCLIMDIV dataset, I calculated the arithmetic mean for annual monthly average temperatures and annual monthly maximum temperatures for each state using the following equation:

Eq. $1 \quad$ Annual Temperature $=\frac{1}{n} \times \sum_{i=1}^{n} x_{i}$ 
where $n$ denotes the number of months in a year and $x_{i}$ denotes the average or maximum temperature for each month. Next, I aligned these annual measures of temperature with the birth year, birth month, and birth state of every individual in the BUNMD dataset and calculated variables representing the average annual temperature in the year leading up to birth and the first through fourth years of life. I calculated the average annual temperature for the year leading up to birth, rather than the approximate nine months of gestation, so that differences in seasonality of conception and birth across decedents do not confound estimation; however, in robustness analyses that yield equivalent results, I estimated models with the nine months of gestation in lieu of the entire year preceding birth. For the robustness models, $n$ in Eq. 1 denotes the nine months of gestation for the year preceding birth.

\section{Model Specification}

I leveraged variation in ambient temperatures within states and within birth months to estimate models predicting age at death using a natural experiment framework. Weather conditions are conceptualized in the model as exogenous, and therefore there is little need for the addition of covariates besides those adjusting for seasonality, year of birth, and state of birth. There is extensive research that documents how later life mortality varies systematically according to season and month of birth (Doblhammer \& Vaupel, 2001). Ambient temperatures have also shifted over time; during the 1896-1940 time period, the average annual temperature increased $3 / 4$ of a degree (i.e. Figure 2). At the same time, cohort effects that occur contemporaneously with temperature patterns during the year of birth as well as cohort effects that occur throughout the life course might confound estimation. These two considerations necessitate adjusting for birth month to address seasonality and birth year to address long-term trends in temperature and birth cohort effects. To address within-state serial correlation, I clustered standard errors at the state-level.

The main model specification was estimated as follows (Eq. 2):

Eq. $2 \quad Y_{\text {iscm }}=\beta_{0}+\beta_{1}$ Temp Year $0_{\text {iscm }}+\beta_{2}$ Temp Year $1_{\text {iscm }}+\beta_{3}$ Temp Year $2_{\text {iscm }}+$ $\beta_{4}$ Temp Year $3_{\text {iscm }}+\beta_{5}$ Temp Year $4_{i s c m}+\gamma_{s}+\delta_{c}+\zeta_{m}+\varepsilon_{i s c m}$

Where $Y_{\text {iscm }}$ refers to the age at death for individual $i$ from state $s$ born in birth cohort $c$ during month $m$; $\beta_{1}$ Temp Year $0_{\text {iscm }}$ refers to a vector of either annual (a) average monthly temperatures, or (b) average maximum temperatures during the 12 months leading up to birth; $\beta_{2}$ Temp Year $1_{\text {iscm }}$ through $\beta_{5}$ Temp Year $4_{\text {iscm }}$ refers to vectors of annual average or maximum temperatures during the postnatal developmental ages of life, age 1 to age $4 ; \gamma_{s}$ refers to a vector of state of birth fixed effects; $\delta_{c}$ refers to a vector of birth cohort fixed effects; $\zeta_{m}$ refers to a vector of birth month fixed effects; and $\varepsilon_{i s c m}$ refers to the error term for each decedent.

\section{RESULTS}

Figure 3 presents results for women and men, separately, for measures of average annual monthly temperatures and average annual maximum temperatures using the CenSoc BUNMD dataset. For women, the coefficients for the year leading up to birth and the first four years of life are generally imprecisely estimated, with exception to a statistically significant coefficient at the $\mathrm{p}<.05$ level for year 3 (average temperature, $\beta=-.0050$, S.E. $=.0022$; maximum temperature, $\beta=-.0040$, S.E. $=.0018$ ). For men, the coefficients for the year leading up to birth and the first four years of life are more precisely estimated, with coefficients that are sizeable and statistically significant for all years. While the coefficients for average temperature are generally uniform over time, the coefficients for maximum temperature attenuate towards zero after the first year of life.

Structural social factors - especially, but not limited to, explicit systems of racism (i.e. Jim Crow laws; redlining, segregation) - throughout the $20^{\text {th }}$ century contribute to differential access to resources and life 
chances across racial/ethnic groups. Figure 4 presents estimates stratified by racial/ethnic groups and sex to account for these structural factors that explain racial health and mortality disparities. The results of this subgroup analysis demonstrate that the overall results are concentrated in the model estimating the ambient temperature-mortality relationship for white men. For all other groups, the effects are smaller in magnitude and not significant below the $\mathrm{p}<.05$ significance threshold. For white men, the effect is largest in Year 0 and Year 1, with attenuation of the coefficients towards zero occurring from Year 2 to Year 4. For the first year of life, a one-point increase in average temperature is associated with a reduction of -.0070 ( $\mathrm{SE}=.0027)$ years of life, while a one-point increase in maximum temperature is associated with a reduction of $-.0078(\mathrm{SE}=.0079)$ years of life.

The difference between the median temperature (51.5) and the $99^{\text {th }}$ percentile (69.1) is 17.6 degrees Fahrenheit. Based on the estimated equation for white men, this is equivalent to a difference of 123 years of life (1.5 months) for the average temperature measure and .137 years of life (1.6 months) for the maximum temperature measure. Between the $1^{\text {st }}$ percentile (36.5) and $99^{\text {th }}$ percentile $(69.1)$, the difference is .228 years of life ( 2.7 months) for the average temperature measure and .254 years of life ( 3.1 months) for the maximum temperature measure.

Figure 5 tests the hypothesis that access to resources might mitigate the association between ambient temperature during the early developmental years of life and later life mortality. In these figures, I present models for men stratified by the educational attainment of the head of household in the 1940 Decennial Census. These models are estimated using the CenSoc Death Master File dataset, which links Social Security Administration death records with the full-count 1940 Decennial Census. The results presented in Figure 5 show that the effect of ambient temperature is smaller and not statistically significant below the $\mathrm{p}<.05$ threshold for men with heads of household who have nine years of schooling or greater; meanwhile, the effect of ambient temperature is sizeable and significant in the year leading up to birth and attenuates over time for men with heads of household who have less than nine years of schooling, in a similar pattern to the overall male results.

Figure 6 further disaggregates these results by race/ethnicity, with two categories: white men and men from all other racial/ethnic categories. Consistent with prior findings, the effect of ambient temperature on mortality are driven by the association specifically for white men from households with less than nine years of schooling.

Overall, these findings indicate little, if any, effect of ambient temperature on women and structurally disadvantaged racial/ethnic groups, but a modest effect for white men. For white men, however, the effect is concentrated for those from less educated households.

\section{DISCUSSION}

Using administrative Social Security death records from the United States, I estimated the impact of within-state temperature fluctuations during the pre- and post-natal developmental periods of life on later life mortality for birth cohorts born between 1896-1940. The findings of this study demonstrate how climate change induced mortality does not just represent a looming, potential threat to older age mortality, but instead has been shaping demographic processes since at least the first half of the $20^{\text {th }}$ century. Indeed, the results indicate that birth cohorts born during this period experienced the intergenerational impacts of climate variation from in utero exposures. These results persist in models that adjust for birth year and birth month fixed effects, which net out seasonal and annual variation in life expectancy.

Crucially, however, the results vary by sex, race/ethnicity, and household educational attainment. This variation might be explained by the complex interplay of biological differences in lifespan across sex and 
social conditions that diminished the health chances of structurally disadvantaged racial/ethnic groups. At the same time, the results demonstrate how high socioeconomic status acts as a safeguard against the relationship between environmental conditions in early life and later life mortality. Importantly, the results demonstrate a long-term ecological association that exists for individuals who have already avoided negative selection from ambient temperature and other environmental pressures through the stages of fecundity, pregnancy, infancy, adolescence, and mid-life. In this respect, the results are most likely an underestimate of the effect of ambient temperature on the full lifespan.

Specifically, the results show that the effect of pre- and post-natal exposure to ambient temperature was only meaningful for white males from low socioeconomic backgrounds. For differences across sex, this finding is consistent with past research that found that male longevity is sensitive to fluctuations in ambient temperature as a result of evolutionary processes that make male fetuses more vulnerable to environmental pressures during gestation (Catalano et al. 2008). According to research by Catalano and colleagues (2008), warmer temperatures in relatively cold regions of the globe are associated with higher male-to-female sex ratios at birth. Consequently, years with warmer temperatures are associated with male birth cohorts with frailer members who otherwise would be negatively selected during birthyears with colder temperatures.

The results are also consistent with prior work documenting disparities in longevity across race/ethnicity as a result of systems of structural racism (Krieger et al., 2014; Satcher et al., 2005; Williams \& Collins, 2001; Williams \& Sternthal, 2010). One study (Feigenbaum et al., 2019), for instance, documents that infectious disease mortality rates for African Americans in cities between 1906-1920 was higher than mortality rates for whites at the height of the 1918 flu pandemic. It is likely that the effect of structural racism on health stratification overshadows the effect of climate variability on later life mortality for Black male birth cohorts, therefore obscuring the association that is otherwise observed for white male birth cohorts.

The association between early life ambient temperature and later life mortality was concentrated for individuals from households that were characterized as having lower levels of education. This finding might be explained by disparities in residential access to electricity, especially during the period prior to 1940, and disparities in residential air conditioning (Barreca et al., 2016). Rural regions with less education expansion were slower to become electrified. Alternatively, this socioeconomic status difference might be explained by differential access to health resources during early life that might offset acute heat-induced illnesses. 
Figure 1. Distribution of Age at Death for BUNMD, Women and Men

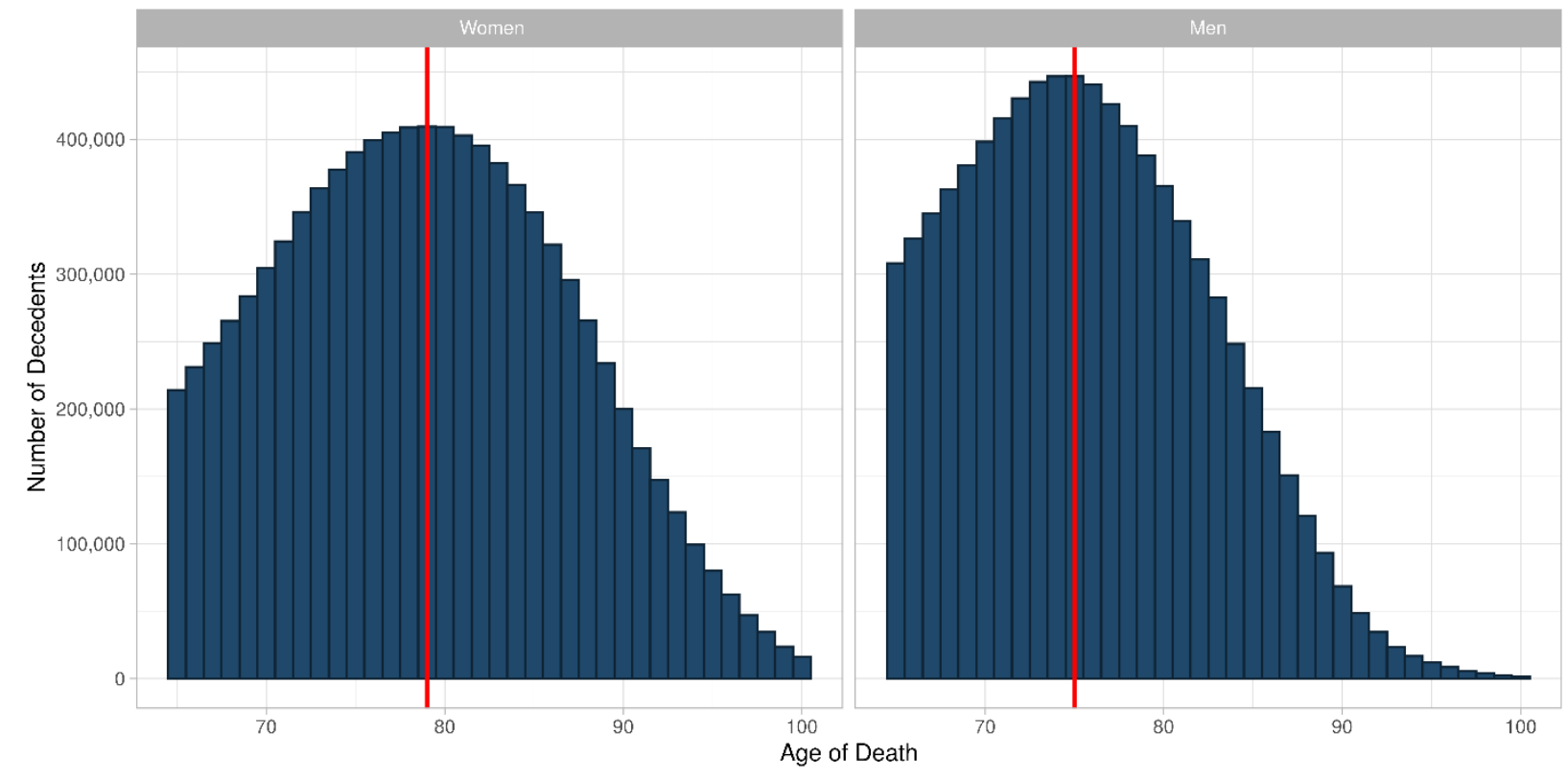

Notes: Vertical red line represents median age of death. 
Figure 2. Annual Average Temperature (Top Panel) and Annual Average Maximum

Temperature (Bottom Panel) in the United States, 1895-2019
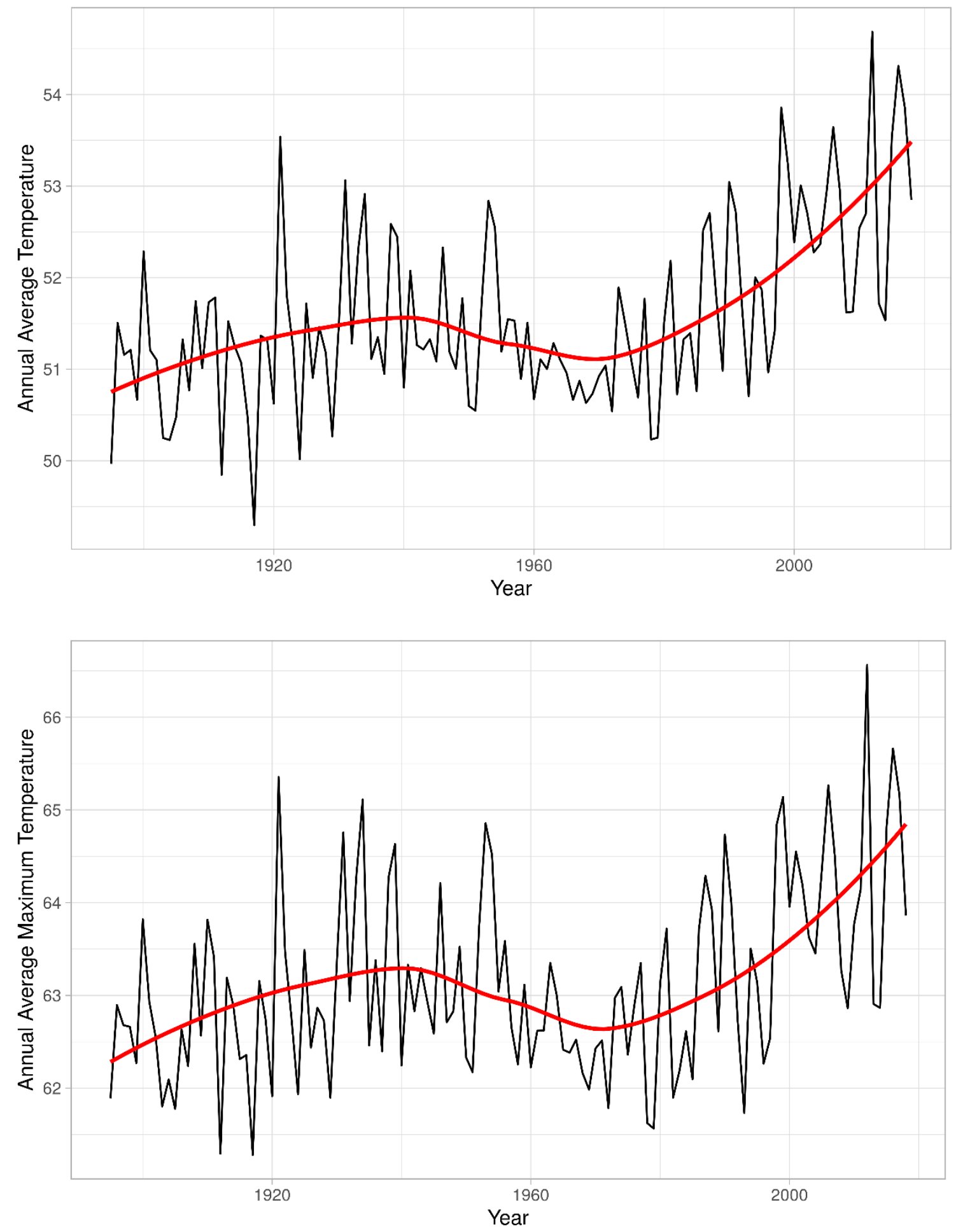

Notes: (a) annual averages are calculated by averaging monthly averages, (b) red lines represents loess smoothed trend lines. 
Figure 3. Models Predicting Later Life Mortality based on Average Temperatures and Maximum Temperatures During Year of Pregnancy and First 4 Years of Life, for Women and Men Separately

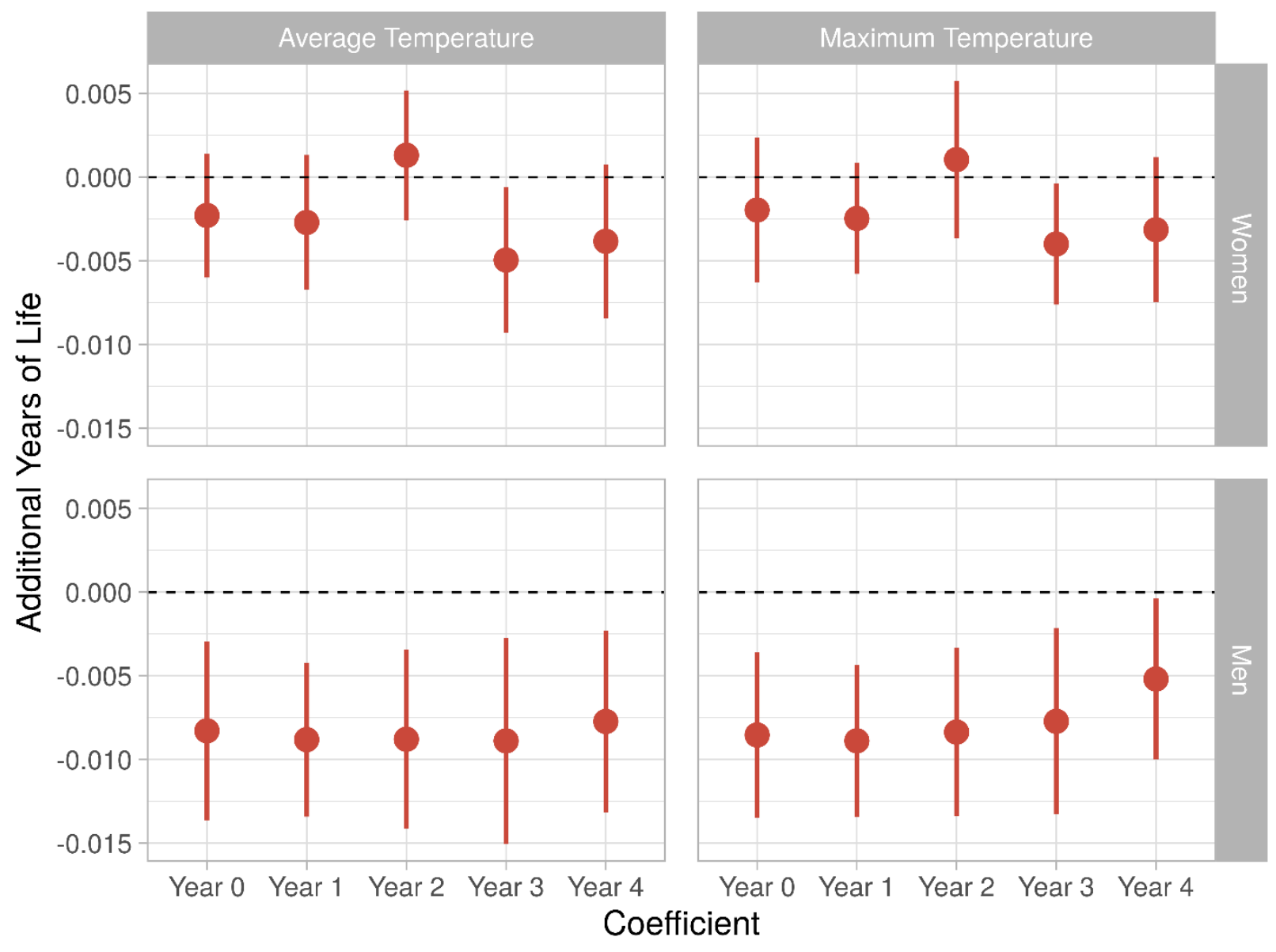


Figure 4. Models Predicting Later Life Mortality based on Average Temperatures and Maximum Temperatures During Year of Pregnancy and First 4 Years of Life, for Women and Men Separately, Stratified by Race/Ethnicity

A. Black Women and Men

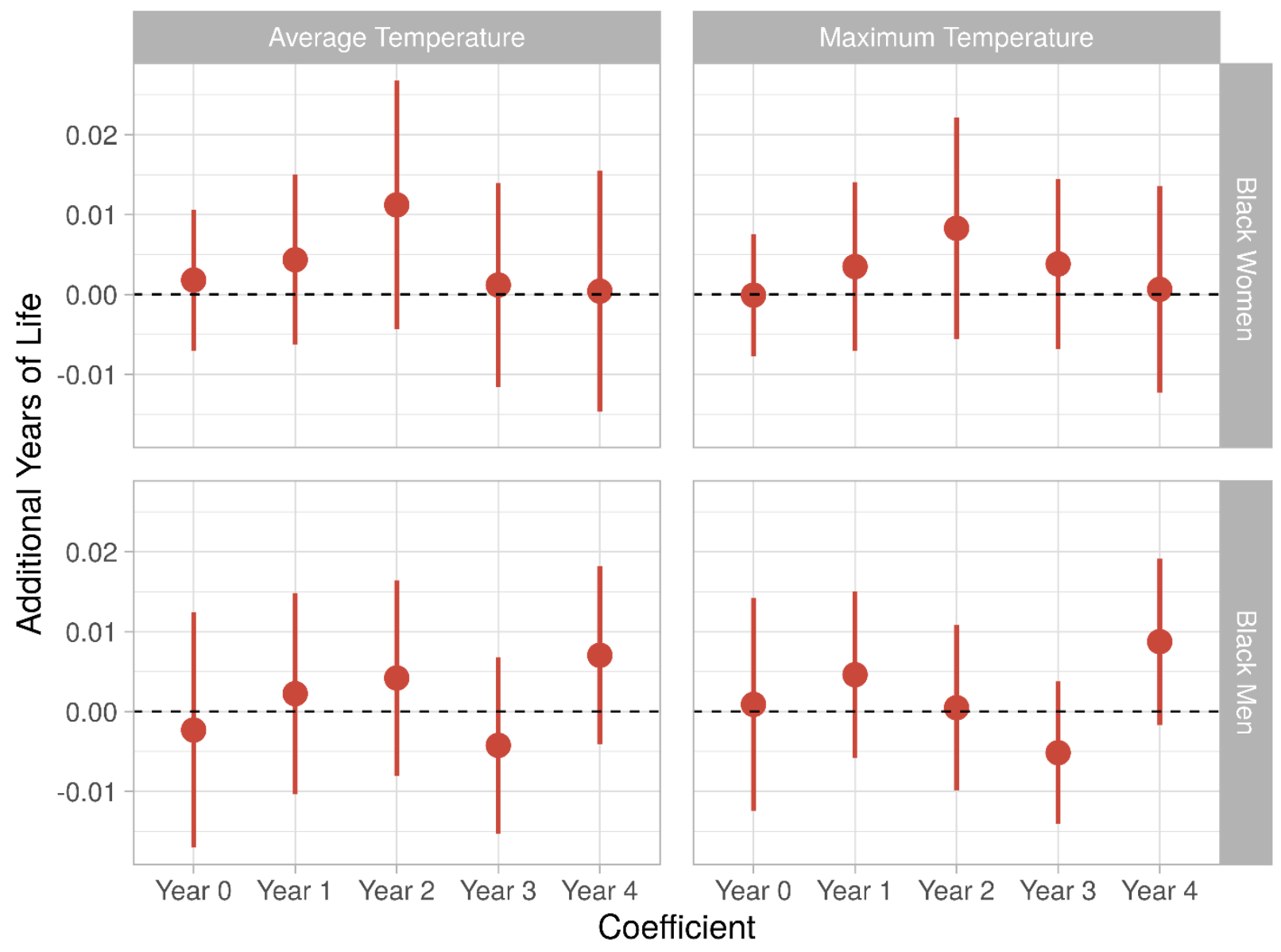


B. White Women and Men

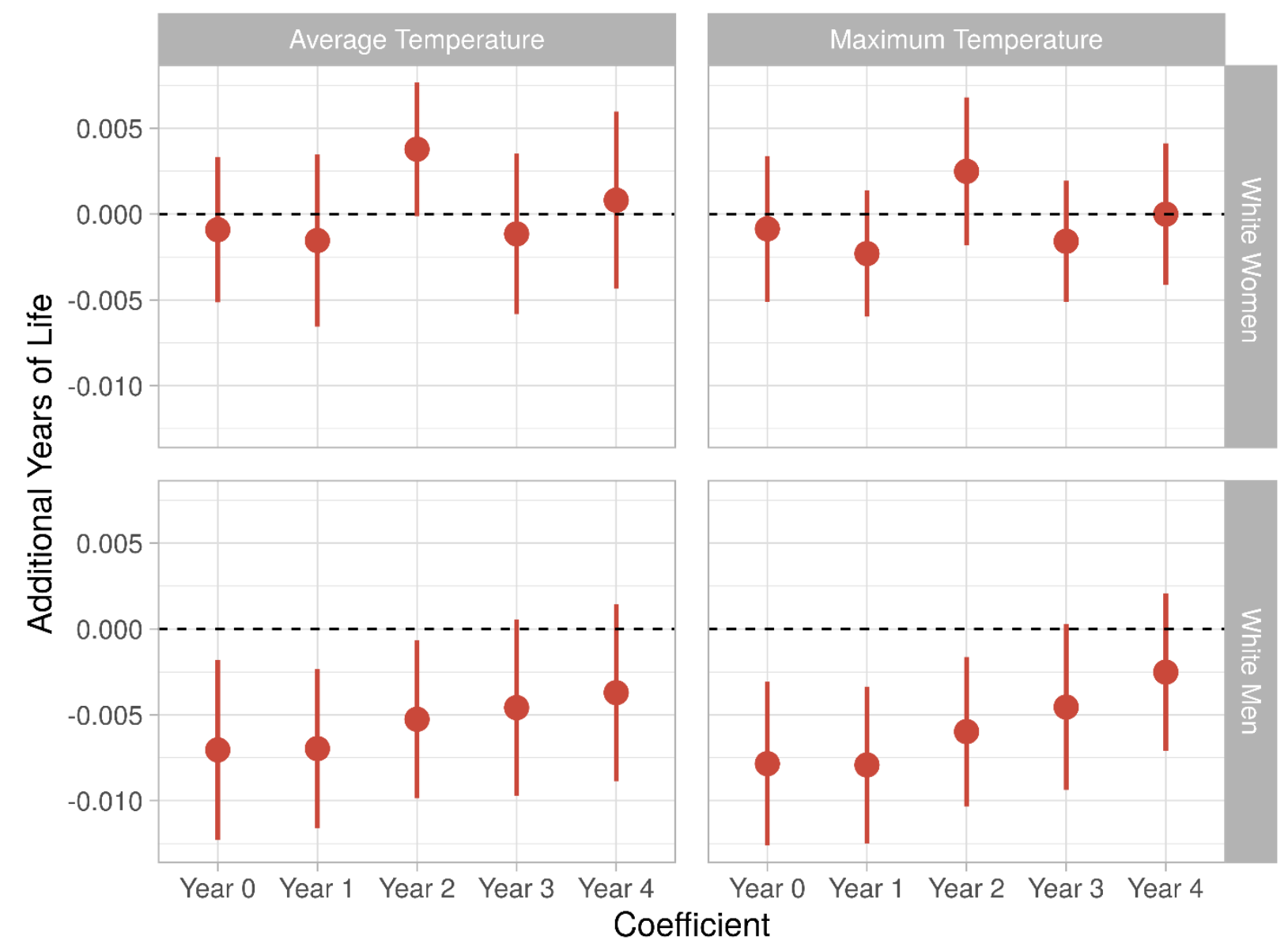


C. Other Race/Ethnicity Women and Men

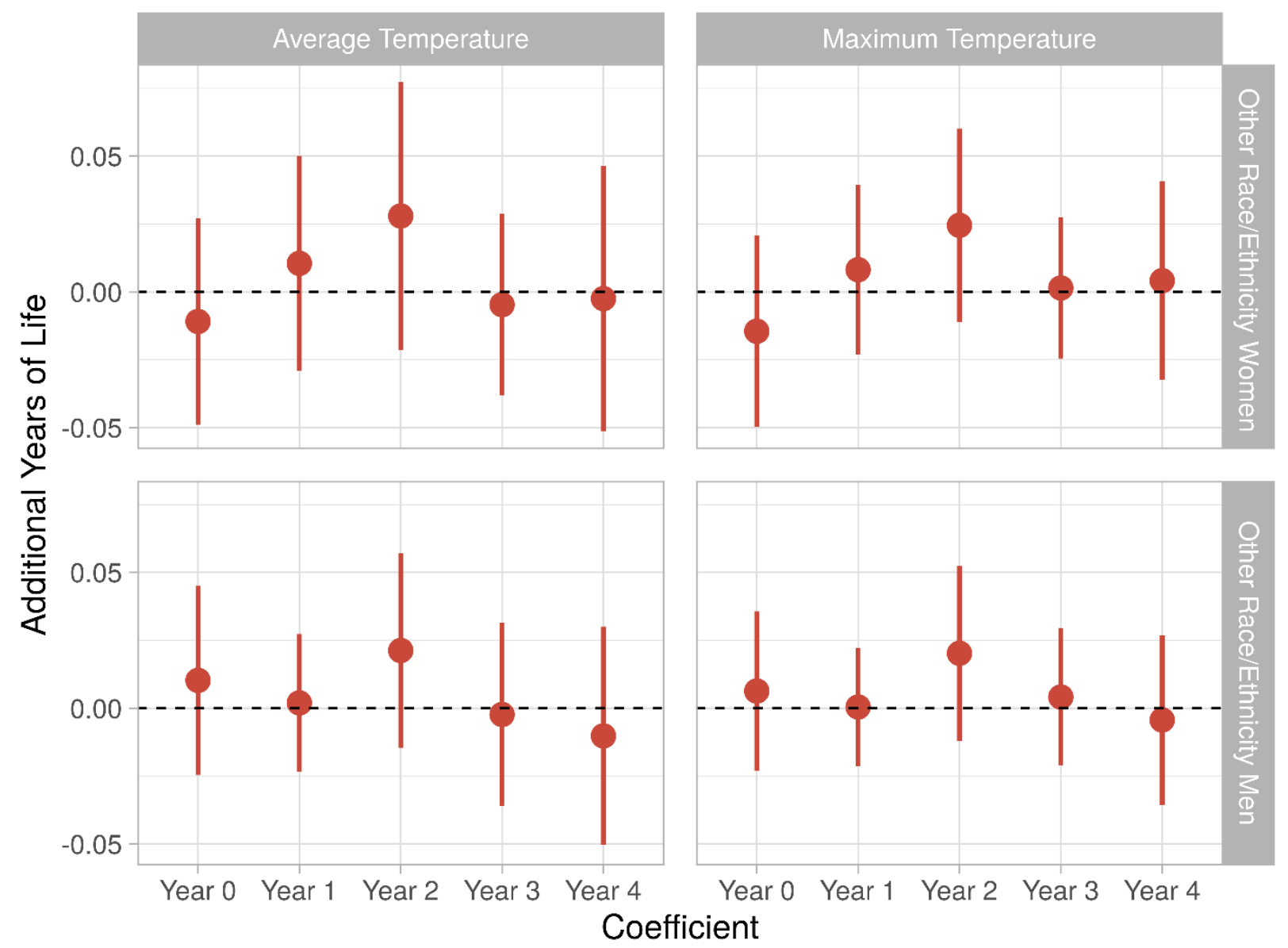


Figure 5. Models Predicting Later Life Mortality based on Average Temperatures and Maximum Temperatures During Year of Pregnancy and First 4 Years of Life, for Men, Stratified by Years of Schooling

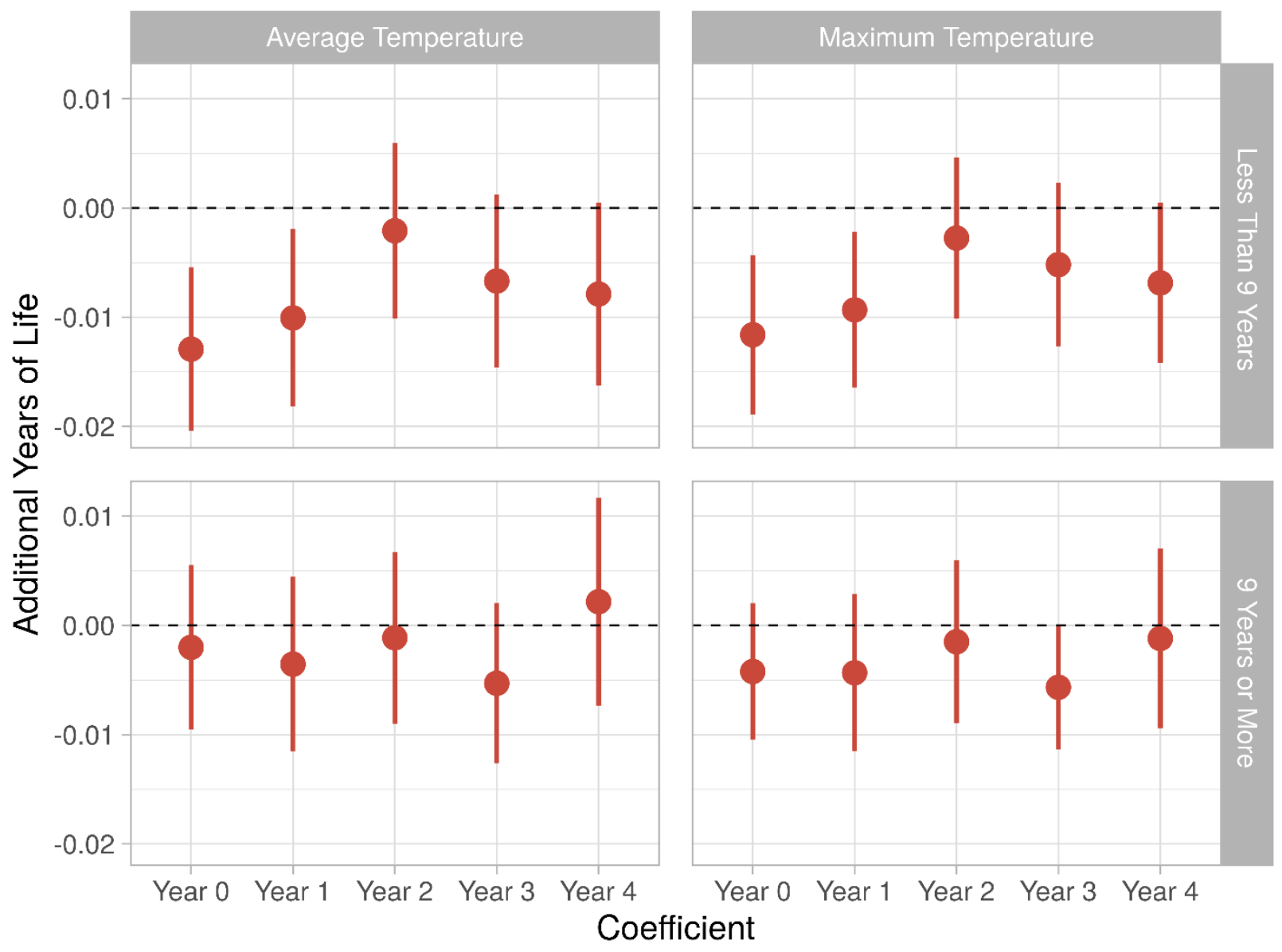


Figure 6. Models Predicting Later Life Mortality based on Average Temperatures and Maximum Temperatures During Year of Pregnancy and First 4 Years of Life, for Men, Stratified by Years of Schooling of Head of Household and Race/Ethnicity

A. White

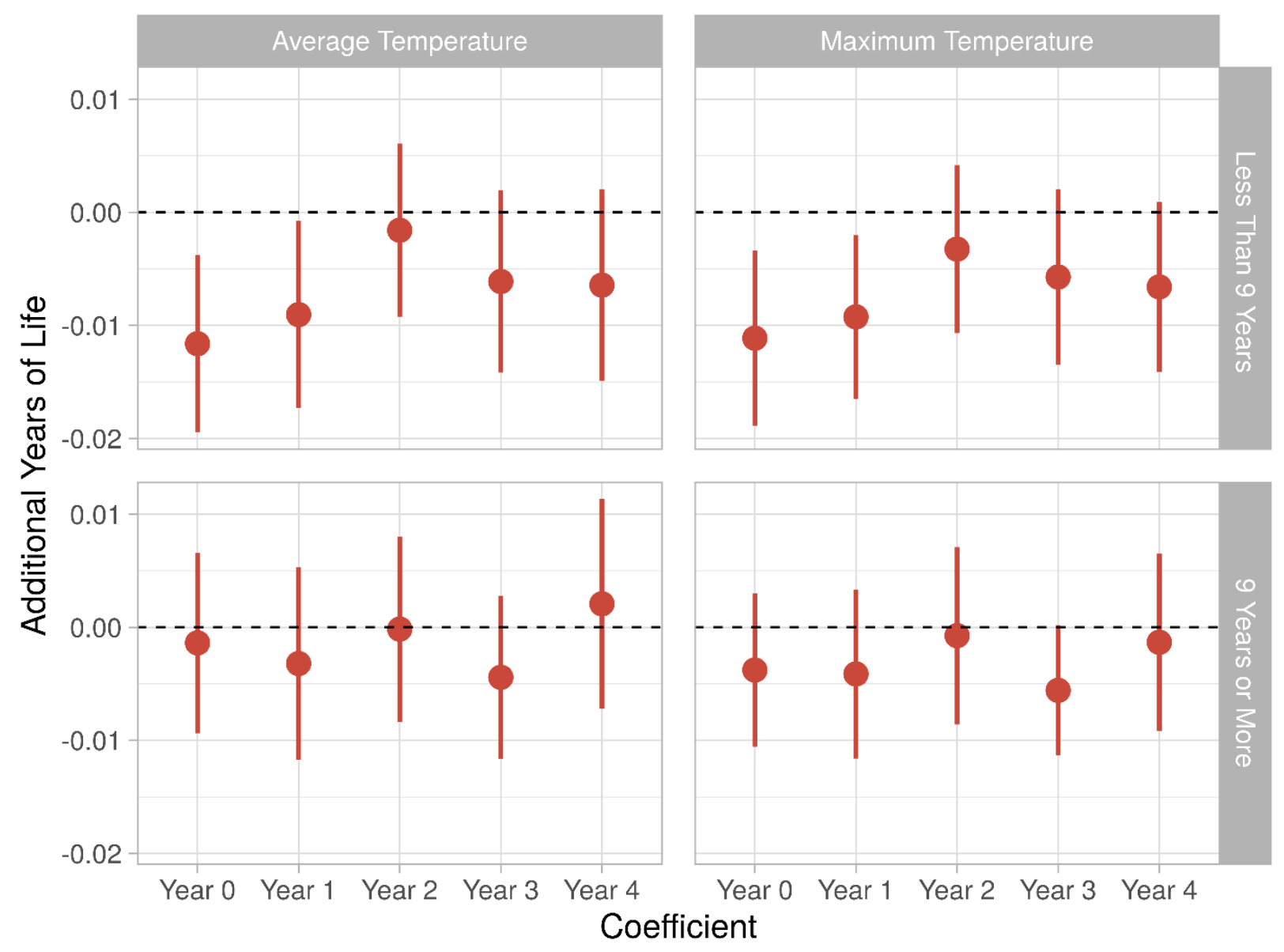


B. Non-white

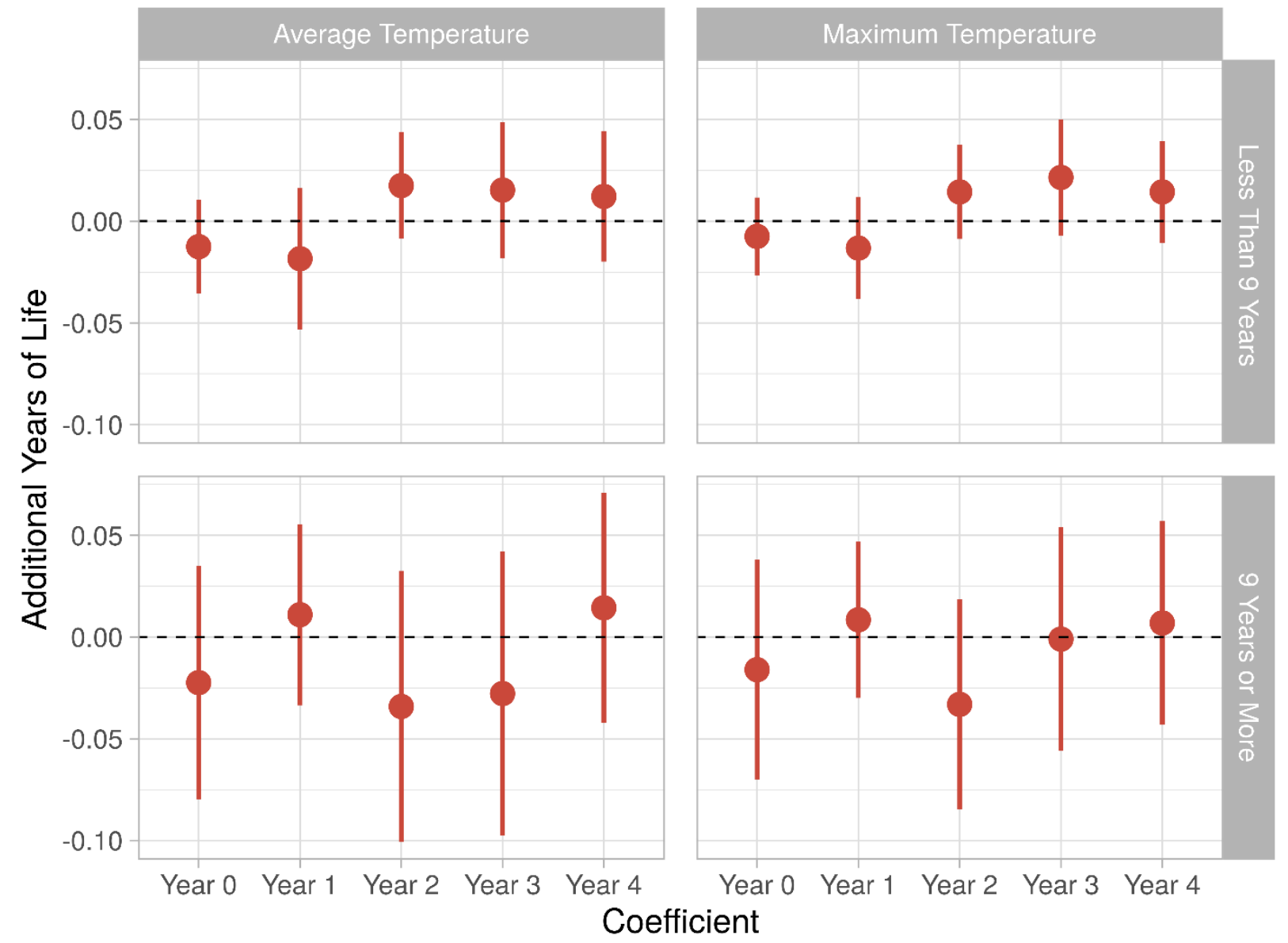




\section{References}

Barreca, A., Clay, K., Deschenes, O., Greenstone, M., \& Shapiro, J. S. (2016). Adapting to Climate Change: The Remarkable Decline in the US Temperature-Mortality Relationship over the Twentieth Century. Journal of Political Economy, 124(1), 105-159. https://doi.org/10.1086/684582

Barron, M., Heft-Neal, S., \& Perez, T. (2018). Long-term effects of weather during gestation on education and labor outcomes: Evidence from Peru (Working Paper No. 134). PERUVIAN ECONOMIC ASSOCIATION.

Basu, R., \& Samet, J. M. (2002). Relation between elevated ambient temperature and mortality: a review of the epidemiologic evidence. Epidemiol Rev, 24(2), 190-202. https://doi.org/10.1093/epirev/mxf007

Bateson, P., \& Gluckman, P. (2012). Plasticity and robustness in development and evolution. Int J Epidemiol, 41(1), 219-223. https://doi.org/10.1093/ije/dyr240

Catalano, R., Bruckner, T., \& Smith, K. R. (2008). Ambient temperature predicts sex ratios and male longevity. Proceedings of the National Academy of Sciences, 105(6), 2244-2247.

Catalano, R. A., Bruckner, T. A., Smith, K. R., \& Saxton, K. B. (2011). Temperature oscillations may shorten male lifespan via natural selection in utero. Climatic Change, 110(3-4), 697-707. https://doi.org/10.1007/s10584-011-0119-4

Chen, X., Tan, C. M., Zhang, X., \& Zhang, X. (2020). The effects of prenatal exposure to temperature extremes on birth outcomes: the case of China. Journal of Population Economics, 33(4), 12631302. https://doi.org/10.1007/s00148-020-00768-4

Curtis, K. J., \& Schneider, A. (2011). Understanding the demographic implications of climate change: estimates of localized population predictions under future scenarios of sea-level rise. Population and Environment, 33(1), 28-54. https://doi.org/10.1007/s11111-011-0136-2

Deschênes, O., \& Greenstone, M. (2011). Climate Change, Mortality, and Adaptation: Evidence from Annual Fluctuations in Weather in the US. American Economic Journal: Applied Economics, 3(4), 152-185. https://doi.org/10.1257/app.3.4.152

Doblhammer, G., \& Vaupel, J. W. (2001). Lifespan depends on month of birth. Proceedings of the National Academy of Sciences, 98(5), 2934-2939. https://doi.org/10.1073/pnas.041431898

Feigenbaum, J. J., Muller, C., \& Wrigley-Field, E. (2019). Regional and Racial Inequality in Infectious Disease Mortality in U.S. Cities, 1900-1948. Demography, 56(4), 1371-1388. https://doi.org/10.1007/s13524-019-00789-z

Hauer, M. E., Fussell, E., Mueller, V., Burkett, M., Call, M., Abel, K., McLeman, R., \& Wrathall, D. (2019). Sea-level rise and human migration. Nature Reviews Earth \& Environment, 1(1), 28-39. https://doi.org/10.1038/s43017-019-0002-9

Isen, A., Rossin-Slater, M., \& Walker, R. (2017). Relationship between season of birth, temperature exposure, and later life wellbeing. Proceedings of the National Academy of Sciences, 114(51), 13447-13452. https://doi.org/10.1073/pnas.1702436114

Kanner, J., Williams, A. D., Nobles, C., Ha, S., Ouidir, M., Sherman, S., \& Mendola, P. (2020). Ambient temperature and stillbirth: Risks associated with chronic extreme temperature and acute temperature change. Environ Res, 189, 109958. https://doi.org/10.1016/j.envres.2020.109958

Krieger, N., Chen, J. T., Coull, B. A., Beckfield, J., Kiang, M. V., \& Waterman, P. D. (2014). Jim Crow and Premature Mortality Among the US Black and White Population, 1960-2009. Epidemiology, 25(4), 494-504. https://doi.org/10.1097/ede.0000000000000104

Luber, G., \& McGeehin, M. (2008). Climate change and extreme heat events. Am J Prev Med, 35(5), 429435. https://doi.org/10.1016/j.amepre.2008.08.021

McMichael, A. J., Woodruff, R. E., \& Hales, S. (2006). Climate change and human health: present and future risks. The Lancet, 367(9513), 859-869. https://doi.org/10.1016/s0140-6736(06)68079-3 
Medina-Ramon, M., Zanobetti, A., Cavanagh, D. P., \& Schwartz, J. (2006). Extreme temperatures and mortality: assessing effect modification by personal characteristics and specific cause of death in a multi-city case-only analysis. Environ Health Perspect, 114(9), 1331-1336. https://doi.org/10.1289/ehp.9074

Molina, O., \& Saldarriaga, V. (2016). The Perils of Climate Change: In Utero Exposure to Temperature Variability and Birth Outcomes in the Andean Region.

Montez, J. K., \& Hayward, M. D. (2011). Early Life Conditions and Later Life Mortality. In R. G. Rogers \& E. M. Crimmins (Eds.), International Handbook of Adult Mortality (pp. 187-206).

Satcher, D., Fryer, G. E., McCann, J., Troutman, A., Woolf, S. H., \& Rust, G. (2005). What If We Were Equal? A Comparison Of The Black-White Mortality Gap In 1960 And 2000. Health Affairs, 24(2), 459-464. https://doi.org/10.1377/hlthaff.24.2.459

Seltzer, N., \& Nobles, J. (2017). Post-disaster fertility: Hurricane Katrina and the changing racial composition of New Orleans. Population and Environment, 38(4), 465-490.

Strand, L. B., Barnett, A. G., \& Tong, S. (2011). The influence of season and ambient temperature on birth outcomes: A review of the epidemiological literature. Environmental Research, 111(3), 451462. https://doi.org/10.1016/j.envres.2011.01.023

Williams, D. R., \& Collins, C. (2001). Racial Residential Segregation: A Fundamental Cause of Racial Disparities in Health. Public Health Reports, 116(5), 404-416. https://doi.org/10.1093/phr/116.5.404

Williams, D. R., \& Sternthal, M. (2010). Understanding Racial-ethnic Disparities in Health: Sociological Contributions. Journal of Health and Social Behavior, 51(1_suppl), S15-S27. https://doi.org/10.1177/0022146510383838

Zanobetti, A., \& O'Neill, M. S. (2018). Longer-Term Outdoor Temperatures and Health Effects: A Review. Curr Epidemiol Rep, 5(2), 125-139. https://doi.org/10.1007/s40471-018-0150-3 